\title{
Faecal flora in neonates with oesophageal atresia
}

\author{
R BAYSTON, T S M LEUNG, AND L SPITZ \\ Nuffield Department of Paediatric Surgery, Institute of Child Health, London
}

\begin{abstract}
SUMMARY The bacteriological findings of a study of intestinal colonisation in 24 neonates with oesophageal atresia are reported. Only five of the patients received antibiotics. When compared with published findings in healthy neonates, the rate of intestinal colonisation in our series was prolonged, with Staphylococcus albus predominating in the first week. Anaerobic colonisation was delayed and bacteroides spp were present in only five patients by the third week. Bifidobacteria were almost completely absent. The onset of intestinal colonisation seemed to be related temporally to enteral feeding. The use of antibiotics in five patients resulted in colonisation by candida in four and clinical thrush in three.
\end{abstract}

Comparative studies of the bacterial colonisation of the intestinal tract show notable differences between breast fed and formula fed neonates. ${ }^{12}$ All the studies have been conducted in normal healthy infants. Rotimi and Duerden ${ }^{3}$ investigated the development of the bacterial flora of the gastrointestinal tract of neonates with congenital abnormalities affecting this structure. The knowledge gained from these investigations may be useful in understanding the role of certain bacteria in the pathogenesis of necrotising enterocolitis and Hirschsprung's enterocolitis. Intestinal colonisation of healthy infants is likely to differ from that of infants with congenital anomalies of the alimentary tract such as atresia or aganglionosis and may be related to differences in enteral feeding regimens and the administration of antibiotics to some infants. A systematic study of bacterial colonisation of the gastrointestinal tract is currently being conducted in this department and the findings in infants born with oesophageal atresia form the basis of this report.

\section{Patients}

Twenty four neonates with oesophageal atresia were admitted to the neonatal surgical unit at the Hospital for Sick Children, Great Ormond Street, London between April 1981 and April 1982. A primary oesophago-oesophageal anastomosis was performed in 18 infants. In addition, 10 of this group had a feeding gastrostomy fashioned, and the remaining 8 had transanastomotic nasogastric intubation. A gastrostomy was performed in the 6 infants in whom primary reconstruction was not possible. Four of these infants subsequently underwent delayed primary anastomosis, while a cervical oesophagostomy was performed in the remaining two infants. Access to the upper gastrointestinal tract was therefore established in all 24 infants within 48 hours of admission. Five patients received antibiotics (ampicillin and cloxacillin) for suspected preoperative pulmonary aspiration.

All infants received intravenous infusion for 48-72 hours postoperatively. Thereafter, expressed breast milk with formula supplements were given either through the gastrostomy or the transanastomotic tube until oral feeding was established by the 7 th postoperative day.

\section{Methods}

Meconium or faeces were collected from each infant daily, or whenever passed, and stored at $4^{\circ} \mathrm{C}$ before being processed in the laboratory. Specimens were always processed within 24 hours. ${ }^{4}$ They were inoculated onto columbia blood agar and MacConkey agar (Oxoid) for aerobic incubation, and neomycin-menadione blood agar, kanamycinvancomycin-menadione lysed blood agar, ${ }^{5}$ and cefoxitin-cycloserine-fructose agar (Oxoid) for anaerobic incubation in nitrogen-hydrogen-carbon dioxide mixture. Cooked meat broth was also inoculated and after two days was subcultured both aerobically and anaerobically onto the above media.

Media for the isolation of bifidobacteria and for candida were used initially, but their routine use was suspended when it became clear that there was no advantage to be gained from this. A sample of 
meconium or faeces equivalent to approximately $0.5 \mathrm{~g}$ was inoculated onto each agar plate and a standard plating technique was used to allow semiquantitative assessment of bacterial numbers. All specimens were tested for antimicrobial activity (which when present was presumed to be due to the presence of antibiotics) by placing approximately $0.5 \mathrm{~g}$ on to the surface of an agar plate seeded with the Oxford strain of Staphylococcus aureus. After incubation the diameters of any zones of inhibition were noted, and the results were used to corroborate stated administration of antibiotics. In addition, an ethanol fixed Gram film from each specimen was examined thoroughly and all organisms noted. Organisms isolated were identified by conventional methods, using laboratory prepared test systems supplemented where necessary by commercial systems (API 20E, API 20A), antibiograms, ${ }^{6}$ and gas liquid chromatography.

\section{Results}

The results from the 19 patients who did not receive antibiotics during the three weeks of the study are shown in Table 1. The numbers of patients whose bowel actions were examined in each week varied as some failed to pass stools for several days at a time. Staph. albus was the organism most frequently isolated, and in a third of the patients studied during the first week it was the only organism isolated. By the second week klebsiella, enterococci, and clostridia were being isolated with greater frequency, and by the third week, klebsiella had become the commonest organism isolated. A comparison of our findings in the first week of life with those of a group of healthy neonates reported by Rotimi et $a l^{7}$ and with 9 cases of oesophageal atresia reported by the

Table 1 Bacteriology in the first three weeks of life in 19 patients not receiving antibiotics (Figures show the percentage of patients growing various bacteria in each week)

\begin{tabular}{|c|c|c|c|}
\hline Organism & $\begin{array}{l}\text { Week I } \\
\left(n=15^{*}\right)\end{array}$ & $\begin{array}{l}\text { Week } 2 \\
\left(n=18^{*}\right)\end{array}$ & $\begin{array}{l}\text { Week } 3 \\
\left(n=15^{*}\right)\end{array}$ \\
\hline Staphylococcus albus & 67 & 67 & 73 \\
\hline Escherichia coli & 27 & 44 & 47 \\
\hline Klebsiella & 13 & 72 & 87 \\
\hline Proteus & 13 & 11 & 7 \\
\hline Enterococci & 7 & 33 & 67 \\
\hline Bacteroides & 7 & 11 & 33 \\
\hline Clostridia & 13 & 44 & 47 \\
\hline ASB + & 7 & 11 & 7 \\
\hline Pseudomonas & 7 & 22 & 27 \\
\hline Bifidobacteria & - & - & 7 \\
\hline No organisms $\ddagger$ & 13 & 6 & - \\
\hline
\end{tabular}

*Not all patients passed bowel actions each week; + -Aerobic spore-bearing bacilli (Bacillus spp); $\ddagger-$ Organisms were not seen on microscopy or grown on culture.
Table 2 Comparison of results in the first week of life in 15 patients not receiving antibiotics with those found in other studies (Rotimi and Duerden $1981,{ }^{7} 1982^{3}$ )

\begin{tabular}{|c|c|c|c|}
\hline & $\begin{array}{l}\text { Oesophageal } \\
\text { atresia } \\
\text { (Bayston et al) } \\
(n=15) \\
\%\end{array}$ & $\begin{array}{l}\text { Healthy } \\
\text { neonates } \\
\left(\text { Rotimi et } a^{7}\right) \\
(n=23) \\
\%\end{array}$ & $\begin{array}{l}\text { Oesophageal } \\
\text { atresia } \\
(\text { Rotimi et al }) \\
(n=9) \\
\%\end{array}$ \\
\hline No organisms & 13 & 0 & $\mathbf{0}$ \\
\hline Escherichia coli & 27 & 82 & 22 \\
\hline Bacteroides & 7 & 78 & 22 \\
\hline Clostridia & 13 & 78 & 66 \\
\hline Staphylococcus albus & 67 & 48 & 78 \\
\hline Staph. albus only & 33 & 0 & $\mathbf{0}$ \\
\hline Bifidobacteria & 0 & 100 & 33 \\
\hline
\end{tabular}

same authors ${ }^{3}$ are shown in Table 2 . No bifidobacteria were found in our patients in the first week, and appeared transiently in only one child in the third week, whereas all of the normal neonates ${ }^{7}$ had acquired this organism within 6 days of birth. Two of our babies still had no organisms in their faeces at the end of the first week, and only one patient had bacteroides compared with 18 of Rotimi et al. ${ }^{3}$ Bacteroides spp were isolated from only five of our patients by the third week of life.

The Figure shows the time of appearance of organisms in the faeces in relation to enteral feeding. As the babies received their first enteral feed on different days depending on their clinical condition, the chronological scale has been adjusted so that day 0 reflects the day on which enteral feeding started. While organisms were isolated in small numbers from three patients before enteral feeding began, most developed their intestinal flora very soon afterwards. The use of a gastrostomy rather than a trans-anastomotic tube for enteral feeding made no difference to the nature or the time of appearance of the organisms.

No bacteria were isolated during treatment from the stools of three of the five patients who received

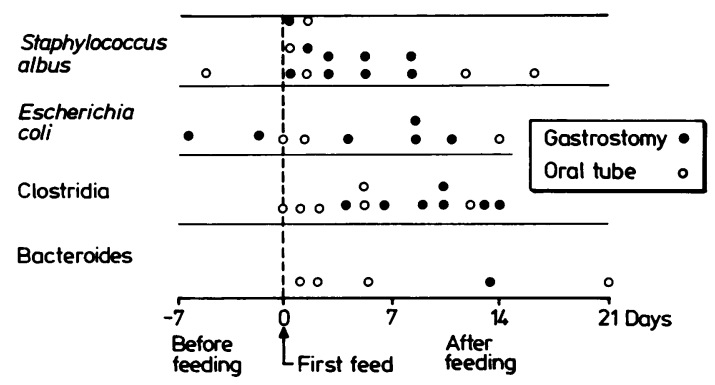

Figure Day on which bacteria first isolated, in relation to enteral feeding. 
Table 3 Species of clostridia isolated from 19 patients not receiving antibiotics

\begin{tabular}{ll}
\hline Species of clostridia & No of patients \\
\hline C. perfringens & 10 \\
C. difficile & 4 \\
C. paraputrificum & 4 \\
C. butyricum & 2 \\
C. innocuum & 1 \\
Unidentified & 2 \\
\hline
\end{tabular}

courses of ampicillin and cloxacillin. Four of these patients became colonised with candida and three developed clinical thrush affecting the mouth and perineum. The clostridia isolated from the patients in the study are shown in Table 3 . Several species were present in some patients. $C$. perfringens and $C$. paraputrificum each appeared in one patient in the first week, and by the end of the second week 6 patients had $C$. perfringens. $C$. difficile, $C$. butyricum, and $C$. innocuum did not appear until the second week. Bacillus spp were isolated transiently from three patients during the study.

Gram film results correlated well with cultural findings. In some cases organisms were isolated in low or moderate numbers when none could be seen on microscopy, but in no case were organisms seen in the Gram film when no growth of the corresponding morphological group was found on culture. No bacteria morphologically resembling bifidobacteria were seen on microscopy.

Results of semiquantitative assessment of bacterial numbers in consecutive specimens from three patients are shown in Table 4 . These patients are representative of the rest. In the case of Staph. albus the numbers on first appearance were almost always low and took a few days to exceed $10^{5} / \mathrm{g}$, whereas other organisms varied in this respect and the aerobic Gram negative rods were usually present in large numbers from the first day on which they appeared. Other than this, the semiquantitative results were unremarkable.

\section{Discussion}

Many of the studies carried out on the bacterial flora of the intestinal tract in neonates and infants have sought differences in the flora of breast fed and formula fed infants. The intestinal flora of the breast fed babies has been shown to consist largely of bifidobacteria $^{8} 910$ until weaning, when coliforms, enterococci, and anaerobes rapidly colonise the gut. ${ }^{11}$ In formula fed babies, while bifidobacteria are still present, the predominating organisms are those usually found in adult faeces. ${ }^{12}$ Rotimi and Duerden ${ }^{6}$ studied healthy neonates in the first week of life in a maternity hospital who were breast fed with formula supplements, and found that only enterococci, streptococci, and staphylococci were present on day 1, with Staph. albus present in $67 \%$. Bifidobacteria, coliforms, bacteroides, and clostridia appeared on the second day in most babies and thereafter a mixed, adult type flora developed. Mata ${ }^{13}$ found that in normal breast fed neonates in a rural Guatemalan community, organisms could be found in the meconium from age 4 hours.

In our study, the rate of colonisation was much slower with a definite sequence. Staph. albus was

Table 4 Examples of semiquantitative results in three patients not receiving antibiotics

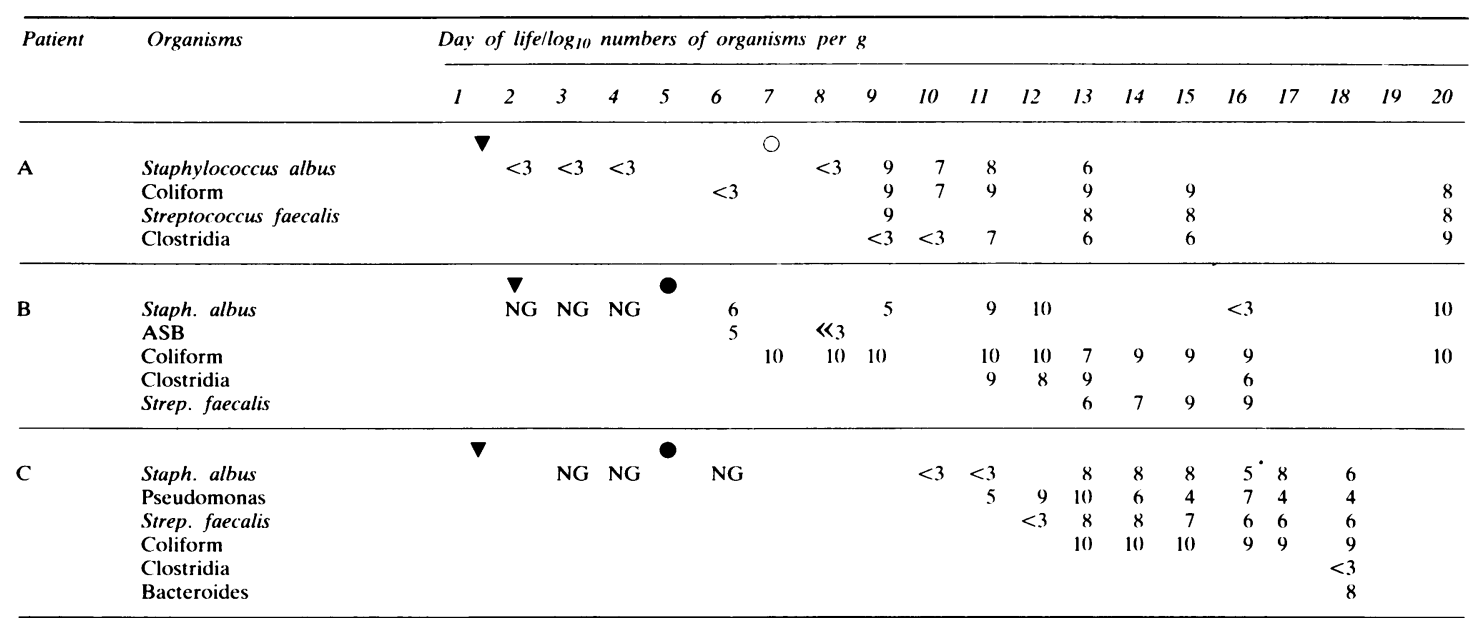

$\boldsymbol{\nabla}=$ anastomosis: $\boldsymbol{O}=$ gastrostomy feed started; $O=$ oral/tube feed started; NG=no growth. 
the first organism to appear in most of the infants, and was the most frequently isolated organism throughout the study. A major difference between our findings and those of others is that, by the end of the first week, half of our infants had only Staph. albus in their stools. Bifidobacteria were almost completely absent in our study, and clostridia and bacteroides were present in fewer patients in the first week than in other studies. Escherichia coli did not appear in any of our infants before day 3 of life, and the peak isolation rate for this organism was in the second week, when it was found in half the infants. Klebsiella was isolated from a gradually increasing number of infants so that this organism appeared in most infants by the end of week 3 of life. In contrast, similar studies carried out over the same period and on the same unit as the 24 cases of oesophageal atresia showed that two infants with ileal atresia and two with functional obstruction all had early onset of intestinal colonisation. The stool specimens obtained on admission from these babies all contained coliforms, clostridia, and Staph. albus and one had bacteroides after 6 days. The patients were all fed at the referring hospital before intestinal obstruction was diagnosed, and they were admitted on days 2 and 3 of life.

Obstetric practices may play a large part in determining the source of intestinal flora in healthy neonates. In most industrialised nations every effort is made to protect the newborn child from the more obvious sources of microorganisms, and many mothers are given enemas to ensure that defecation does not occur during labour. In less well developed communities, the birth is attended by folk midwives and defecation by the mother during delivery commonly occurs. ${ }^{14}$ The mother's intestinal tract, and indirectly her genital tract, are considered to be the natural source of the baby's intestinal flora. ${ }^{15}$ This is supported by the finding in one study of the same strains of $E$. coli in mother and baby, and from mucus removed from the baby's mouth after delivery. ${ }^{16}{ }^{17}$ In industrialised societies, when babies are kept in hospital, and particularly if separated from their mothers, they may become colonised by organisms from the hospital staff and environment. This has been illustrated in the case of klebsiella by Shinebaum et al. ${ }^{18}$ We consider it possible that the babies in our study were colonised from the hospital staff and environment, rather than from their mothers, due mainly to the lack of continuity from mouth to stomach caused by their anomaly, and to their early transfer to an intensive care ward. We feel that this may have dictated the pattern of colonisation in our series. Similar results have been published recently, ${ }^{3}$ though all the neonates with oesophageal atresia in that study received antibio- tics. Times and routes of feeding in relation to onset of colonisation were not discussed by these authors, who found that organisms appeared in the stools soon after operation. The relatively short time between operation, feeding, and appearance of organisms in the stools in our study makes it impossible to state with certainty whether the gut became colonised as a result of organisms entering during operation or as a result of access to the intestine by means of either a gastrostomy or an oesophageal anastomosis, or as a result of feeding. Six of the patients in our study did not, however, undergo early primary oesophago-oesophageal anastomosis and only a gastrostomy was fashioned. In the five patients in this group whose data are sufficiently comprehensive, there was a delay of two days before feeding began via the gastrostomy, and this was followed one day later by the onset of colonisation. This suggests that feeding is the main factor leading to the onset of colonisation.

The reason why colonisation of the intestine did not develop until enteral feeding began may be simply that a substrate became available which allowed bacterial multiplication. The increased opportunity for inoculation of bacteria into the alimentary tract along with the feed may also be important, however, and curds may protect swallowed organisms from the action of acid in the stomach.

The delay in colonisation of the intestinal tract in neonates with oesophageal atresia means that the vitamin $\mathrm{K}$ normally produced by the enteric flora is not available. Though most babies are given one dose of vitamin $\mathrm{K}$ at birth, the half life of this substance is variable and some babies may possibly require an additional dose at 2 or 3 weeks of age, particularly if further surgery is planned.

The delay in colonisation may also have a deleterious effect on the immunological development. This may result in a general developmental immunological retardation and defective opsonisation. This may be particularly important in the first few years of life because of the inability to initiate the alternative complement pathway during this period. This may mean that these babies, while not showing the overt features of immunological deficiency, may have an impaired ability to combat infections, at least until the immunological system matures sufficiently to make the alternative complement pathway less important. These immunological aspects are currently being studied.

The results in the five infants who received antibiotics show that the intestinal flora can be completely eradicated exposing the alimentary tract to colonisation by resistant organisms which may give rise to serious infections. Prophylactic anti- 
biotics would seem to be unnecessary and indeed contraindicated in most neonates with oesophageal atresia, but if required because of suspected aspiration they should be given for as short a period as possible.

We thank the nursing staff of ward $6 \mathrm{~A}$ at the Hospital for Sick Children, Great Ormond Street, for collecting specimens so diligently.

\section{References}

${ }^{1}$ Hall IC, O'Toole E. Bacterial flora of first specimens of meconium passed by fifty new-born infants. Am J Dis Child 1934;47:1279-85.

${ }^{2}$ Hall IC, O'Toole E. Intestinal flora in new-born infants. With a description of a new pathogenic anaerobe, bacillus difficilis. $\mathrm{Am}$ $J$ Dis Child 1935;49:390-402.

3 Rotimi VO, Duerden BI. The bacterial flora of neonates with congenital abnormalities of the gastro-intestinal tract. $J$ Hyg 1982;88:69-81.

${ }^{4}$ Crowther JS. Transport and storage of faeces for bacteriological examination. J Appl Bacteriol 1971:34:477-83.

5 Finegold SM, Sugihara PT, Sutter VL. Use of selective media for isolation of anaerobes from humans. In: Shapton DA, Board RG, eds. Isolation of anaerobes. London: Academic Press, 1971:99-108.

${ }^{6}$ Sutter VL, Finegold SM. Antibiotic disc susceptibility tests for rapid presumptive identification of gram negative anaerobic bacilli. Appl Microbiol 1971;21:13-20.

${ }^{7}$ Rotimi VO, Duerden BI. The development of the bacterial flora in normal neonates. J Med Microbiol 1981;14:51-62.

${ }^{8}$ Bullen CL, Tearle PV, Willis AT. Bifidobacteria in the intestinal tract of infants: an in-vivo study. $J$ Med Microbiol 1976;9:325-33.
${ }^{9}$ Bullen CL, Tearle PV. Bifidobacteria in the intestinal tract of infants: an in-vitro study. J Med Microbiol 1976;9:335-44.

${ }^{10}$ Bullen CL. Tearle PV, Stewart MC. The effect of 'humanised' milks and supplemented breast feeding on the faecal flora of infants. J Med Microbiol 1977;10:403-13.

11 Stark PL, Lee A. The microbial ecology of the large bowel of breast-fed and formula-fed infants during the first year of life. J Med Microbiol 1982;15:189-203.

12 Long SS, Swenson RM. Development of anaerobic faecal flora in healthy newborn infants. $J$ Pediatr 1977;91:298-301.

${ }^{13}$ Mata LJ, Mejicanos ML, Jimenez F. Studies on the indigenous gastrointestinal flora of Guatemalan children. Am J Clin Nutr 1972;25:1380-90.

${ }^{14}$ Mata LJ, Urrutia JJ. Intestinal colonization of breast-fed children in a rural area of low socio-economic level. Ann NY Acad Sci 1971;176:93-109.

15 Gothefors L, Carlsson B, Ahlstedt S, Hanson LÅ, Winberg J. Influence of maternal gut flora and colostral and cord serum antibodies on presence of Escherichia coli in faeces of the newborn infant. Acta Paediatr Scand 1976;65:225-32.

${ }^{16}$ Bettelheim KA, Breadon A, Faiers MC, O'Farrell SM, Shooter RA. The origin of $\mathrm{O}$ serotypes of Escherichia coli in babies after normal delivery. J Hyg 1974;72:67-70.

${ }^{17}$ Bettelheim KA, Teoh-Chan CH, Chandler ME, et al. Further studies of Escherichia coli in babies after normal delivery. J Hyg 1974;73:277-85.

${ }^{18}$ Shinebaum R, Cooke EM, Brayson JC. Acquisition of Klebsiella aerogenes by neonates. J Med Microbiol 1979;12:201-5.

Correspondence to $\operatorname{Dr} \mathrm{R}$ Bayston, Nuffield Department of Paediatric Surgery, Institute of Child Health, London WC1N 3JN.

Received 15 September 1983 